\title{
Collective Anxieties of Canadians During The COVID-19 Pandemic: The Angst-Free and Anxious Population Segments ${ }^{1}$
}

\author{
Fernando Mata \\ School of Sociological and Anthropological Studies, University of Ottawa, Canada, \\ E-mail:fmata@uottawa.ca \\ November 12, 2020
}

Keywords: Collective Anxieties, Market Segmentation, COVID-19 Pandemic, Canada

\begin{abstract}
The COVID-19 Pandemic in Canada represents a very troubling period as individuals confront a powerful "invisible" enemy killer in the form of the COVID-19 virus. This historical juncture is important to analyze because it constitutes a moment where collective anxieties become widespread and collective resources are mobilized to address them. Using market segmentation analysis, the purpose of the study is to produce a portrait of collective anxieties, paying special attention to the typical population segments in the Canadian population differentiated by their particular concerns about health and social conditions in the country and the world. The study used as its data source a survey sample of 4,600 adult Canadians aged 15 years old and over during the confinement period of March 292020 to April 32020 and collected by Statistics Canada. Attitudinal domain items (12 in total) included concerns about personal and household health, the health system, the ability to cooperate and support during and after the crisis, family stress and others. A market segmentation analysis using Principal Components and k-means cluster analysis of these domain items revealed the presence of six major population segments: Health Conditions Anxious (13\%), Health System Overload Anxious (26\%), Angst-Free (23\%), Inner-Bubble Conditions Anxious (12\%), Outer-Bubble Conditions Anxious (25\%) and World Conditions Anxious (1\%). The segment mottos were as follows: "Glad I Have A Health Card!", "How Many Beds Do We Have?", "I'm Not Worried!, "My Bubble May Be In Trouble!", "Other Bubbles May Be In Trouble! and "It's the End of the World As We Know It!". Inner-Bubble Conditions Anxious members displayed the higher average scores of collective anxiety and Angst-Free members, the lowest. Market segmentation is a useful tool for decision makers to categorize population members by their typical attitudinal traits and, by doing so, facilitate better public campaigns, help design messages, and implement changes that can promote more efficient ways to deal with the various psychosocial consequences of the COVID-19 confinement.
\end{abstract}

\footnotetext{
I Paper to be presented at the 2021 CSA Meetings, Edmonton-Alberta. The author would like to thank Stein Monteiro, Jennifer Dumoulin, the Ontario Data Documentation, Extraction Service and Infrastructure (ODESIScholars Portal Statistics) as well as Statistics Canada for making available the data and valuable support and guidance.
} 


\subsection{Background}

According to Strong (1990) a major outbreak of a fatal epidemic disease is generally followed by plagues of fear, panic, suspicions and stigma. During epidemics such as the present COVID-19 outbreak happening in Canada, there is an elevated level concern for personal and family safety as well as dread about the human condition in general. In the context of epidemics, Hunt (1999) defines collective anxieties as responses to "perceived situations of danger, whether real or imagined" (p.509). Through a mechanism of "amplification", individuals may project anxieties from personal domains to more impersonal ones such as their neighbourhoods, communities, countries and even the world (Hume, 2000). Studying the collective anxieties occurring during an epidemic involves a systematic examination of facets such as the degree of suspicion in catching the disease, routes of disease contagion such as breathing or touching surfaces, the evaluation of self-protection and family protection mechanisms as well the perceived negative outcomes of the epidemic occurring in society (Kelly, 1990; Da Silva et al., 2020).

The COVID-19 virus has caused major disruptions across the world, after being declared as a pandemic by the World Health Organization (WHO) on January 312020 (WHO, 2020). This pandemic has led to several disruptions for most of the world's population. In Canada, the first cases of infections were observed in travellers from $\mathrm{China}^{2}$ and reported to the press in January 2020. Given a steady climb in cases, on March 25 2020, an emergency aid bill passed and Canada made 14-day quarantine mandatory for all arrivals. Three days later Prime Minister Trudeau announced a ban on air travel for those with COVID symptoms. Canada is presently undergoing the so-called "second" phase. As of October 25 2020, there had been a total of 9,946 deaths attributed to the COVID-19 virus in Canada ${ }^{3}$. A larger number is expected in the coming months. Most of the reported cases are in Canada's two most populous provinces, Ontario and Quebec, which have declared different sanitary measures and confinement restrictions to deal with virus spread in the population.

The collective anxieties manifested in the Canadian population configure a set of potential market segments. Market segments are groups of individuals who are very similar in their reaction to one or more mix of environmental elements, and as such, can be targeted by public health campaigns aimed at promoting social well-being (Grover and Briens, 2006). In a psychographic segmentation analysis, for instance, individuals are divided into different groups on the basis of psychosocial characteristics (Lin, 2002). This technique divides the market into segments on the basis of interest, values, opinion, personality characteristics, attitudes using techniques of factor analysis, cluster analysis and canonical correlation (Tynan and Drayton, 1987).

Using a sample of the adult population of Canada, the central objectives of the marketing segmentation analysis presented here is to break down the population into meaningful clusters of individuals (homogeneous) in terms of their psychographic traits during the COVID-19 pandemic. Three central questions guided the segmentation analysis: 1) What COVID-19 related anxieties are the most commonly reported by Canadians during the pandemic? 2) Can groups of individuals be differentiated into attitudinal segments or clusters according to their types of anxieties? and 3) What are the typical socio-

\footnotetext{
2 Source: https://nationalpost.com/pmn/news-pmn/canada-news-pmn/timeline-of-covid-19-cases-incanada-2.

3 Source: https://www.statista.com/statistics/1107079/covid19-deaths-by-province-territory-canada.
} 
demographic, residential, employment and other psychosocial characteristics of the members of these segments? The CPSS-Series1 survey conducted by Statistics Canada was regarded as an ideal data source chosen to empirically explore these three central research questions and produce a statistical portrait of collective anxieties during the pandemic ${ }^{4}$.

\subsection{Sample and Measures}

The Canadian Perspective Survey Series1 (CPSS Series1) entitled "Impacts of COVID-19" is the first of a series of voluntary online surveys that collected information on knowledge and behaviours of approximately 4,600 Canadians aged 15 years old and over who were residents of the 10 Canadian provinces. It was administered by Statistics Canada between March 292020 to April 32020 (the reference week). The probability panel of the CPSS-Series 1 was created by randomly selecting a subset of the Labour Force Survey (LFS) respondents. The CPSS Series 1 survey collected a wide range of information on activities related to health impacts of the pandemic, routine activities, information on COVID-19, social distancing practices among others ${ }^{5}$.

A total of 12 collective anxiety scales were used for this analysis. These tapped into COVID-19 perceived concerns attached to various personal, health and societal domains in the context of the pandemic. Scales were measured as four point scores ones $(1=$ not at all concerned, $2=$ somewhat concerned, $3=$ very concerned and $4=$ extremely concerned) which were treated as indicators of low, moderate, high and very high anxiety levels respectively. The following general question was asked in the CPSS Series 1 survey: How concerned are you about each of the following impacts of COVID-19? (list provided). The roster of collective anxiety scales items ranked by their average scale scores is presented in Table 1. Concerns regarding the overload of the health system and vulnerable peoples' health ranked at top levels of rating in terms of the sources of collective anxiety.

\subsection{Statistical Methods and Segment Identification}

Principal Component Analysis (PCA) and k-means cluster analysis were used as the main statistical techniques for segment identification (see detail of the methodologies followed in Punj and Stewart (1983), Grover and Vriens (2006) and Salkind and Rasmussen (2010). In the first phase, Principal Components (statistical technique aimed at data reduction) extracted 3 major dimensions underlying information contained in the 12 scales of collective anxieties related items. In the second phase, using component scores of these dimensions capturing $62 \%$ of the total data variation, $\mathrm{k}$-means clustering analysis was applied to the CPSS-Series 1 data. This clustering algorithm was developed to sort survey respondents into a $\mathrm{k}$ number of clusters through assignments and re-assignments based on the shortest distance between the

\footnotetext{
${ }^{4}$ This study is the second market segmentation study carried out using CPSS data. The first one, focusing on routine activities which used CPSS-Series2 data, is available at: https://osf.io/preprints/socarxiv/6vumh/ 5 Statistics Canada has already released major findings of the CPSS-Series 1, Series 2 and CPSS-3 surveys (conducted between March 29-April 32020 and June 15-21 2020 respectively), which include: greater anxieties over personal health and the health of others, that most Canadians were following health guidelines, greater time spent on the internet and watching television, women were stricter in terms of following guidelines than men, and youth were less likely to wear masks in public. Sources : 1) https://www150.statcan.gc.ca/n1/daily-quotidien/200408/dq200408c-eng.htm; 2) https://www150.statcan.gc.ca/n1/daily-quotidien/200708/dq200708a-eng.htm.
} 
individual and the centroid (mass centre) of the cluster. The distance measure chosen for this purpose was the Euclidean distance squared. For the cluster analysis $k=2$ to $k=8$ segment solutions were tested. The $\mathrm{k}=6$ solution proved to be the most valid and informative according to the parsimonious reduction of the Within Sum of Squares (WSS) and the application of the "elbow" criteria as a stopping rule in the partition of clusters (see technical appendix chart A$1)$.

The validation of the partition of the population into six clusters was verified using Analysis of Variance (ANOVA) F tests where the cluster membership was used in the prediction of the socio-demographic and attitudinal characteristics of respondents (see table A-2 in the technical appendix). The highest predicted power of the cluster partition was found in reference to the immigrant status of individuals and the perceived mental health traits $(3 \%$ of variance explained each). The average inter-correlation between all items found was $r=.42$. The highest inter-correlations found were between Canada's Health and World Health (r=.76) and Canada's Health and Overload of the Health System item $(r=.53)$

Table 1: Average Score of Collective Anxiety Scales of COVID-19 ranked by their Greater Level of Concern, Canadian Adults, 2020

\begin{tabular}{|r|l|r|r|}
\hline $\begin{array}{c}\text { Item } \\
\text { Number }\end{array}$ & \multicolumn{1}{|c|}{$\begin{array}{c}\text { Collective Anxiety Scales (1-4 points), } \\
\text { concerned about: }\end{array}$} & $\begin{array}{c}\text { Mean of } \\
\text { Scale } \\
\text { Score }\end{array}$ & $\begin{array}{c}\text { Std. } \\
\text { Deviation }\end{array}$ \\
\hline 1 & Overloading of the health system & 3.28 & 0.77 \\
2 & Vulnerable people's health & 3.16 & 0.83 \\
3 & World population's health & 2.93 & 0.82 \\
4 & Canadian population's health & 2.90 & 0.76 \\
5 & Member of household's health & 2.66 & 0.94 \\
6 & Civil disorder & 2.40 & 0.94 \\
7 & Ability to cooperate and/or support during crisis & 2.38 & 0.89 \\
8 & My own health & 2.36 & 0.87 \\
9 & Ability to cooperate and/or support after crisis & 2.28 & 0.94 \\
10 & Maintaining social ties & 2.21 & 0.91 \\
11 & Family stress & 2.17 & 0.97 \\
12 & Violence in the home & 1.29 & 0.72
\end{tabular}


4.0. Findings

\subsection{Segment Prevalence and Traits}

According to the cluster analysis of the CPSS-Series 1 data, six uniquely profiled groups of the Canadian adult population respondents were identified. Their membership was distributed as follows: $13 \%$ in segment $1,26 \%$ in segment $2,23 \%$ in segment $3,12 \%$ in segment $4,25 \%$ in segment 5 and $1 \%$ in segment 6 . Based on the typical activity profiles drawn from the 26 collective anxiety scales, the segments were labeled as follows: Segment 1 - "Health Conditions Anxious", Segment 2-"Health System Overload Anxious", Segment 3-"Angst-Free", Segment 4"Inner-Bubble Conditions Anxious", Segment 5-"Outer-Bubble Conditions Anxious" and Segment 6 "World Conditions Anxious". The prevalence ${ }^{6}$ (adult population \% share) of these segments is presented in pie chart 1.

Chart 1: Segment Prevalence in the Canadian adult population during the COVID19 Pandemic, Collective Anxiety Domains, Canadians aged 15 years old and over

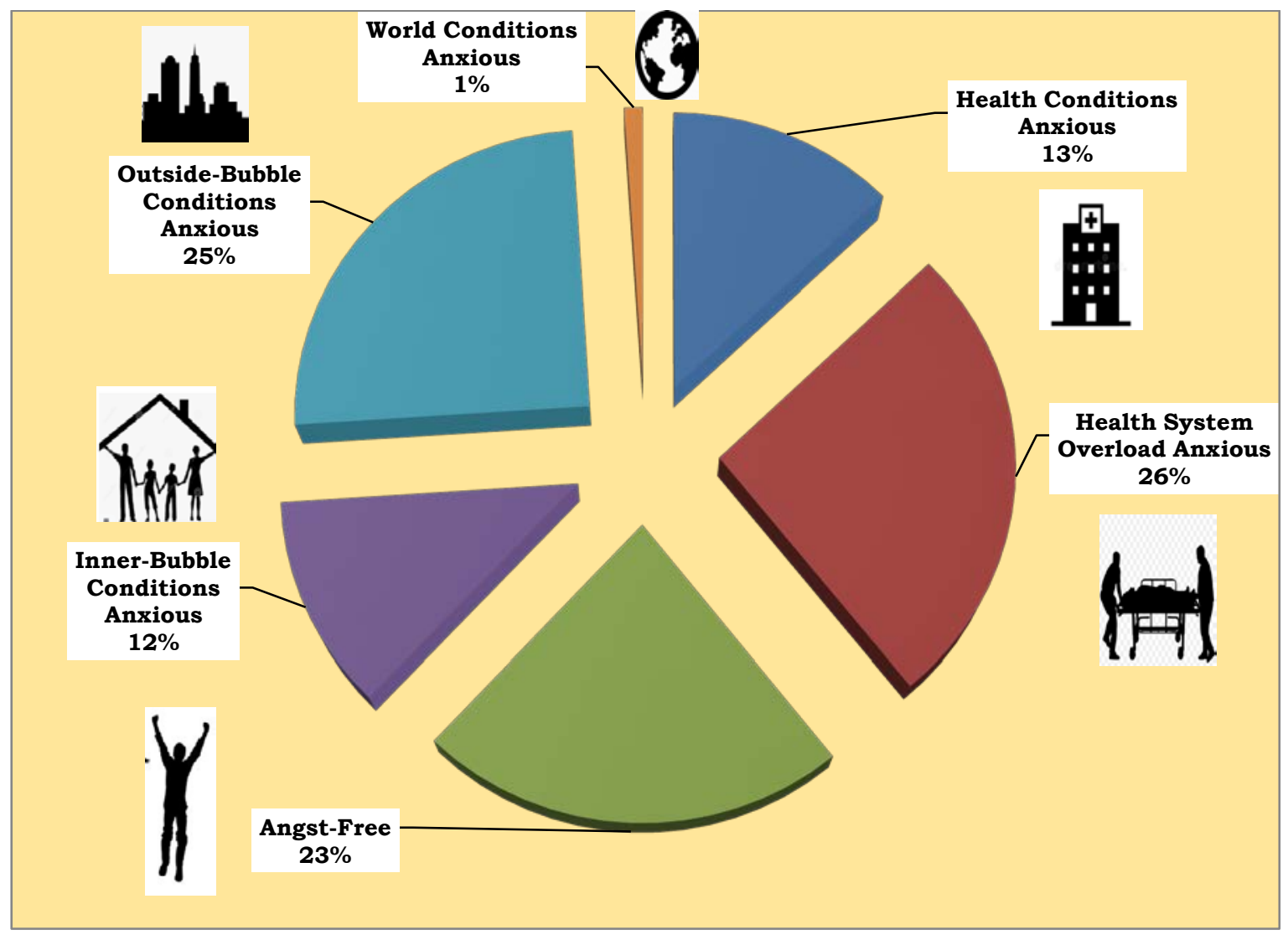

Source: CPSS-Series 1 Survey, Statistics Canada, 2020

6 Population estimates were obtained using weighted frequencies. 
A visual representation (PCA bi-plot) of the vector of collective anxiety items and dimensions underlying the data are displayed in chart 2 . The first two components extracted by PCA accounted for $44.6 \%$ of the variance of all activity items. The first dimension represented by $\mathrm{C} 1$ (31.0\% of the total variance of items) opposed as polar cases members of the AngstFree segment vs. the rest of segments in terms of a lesser or higher degree of anxiety regardless of their types. The second dimension, represented by $\mathrm{C} 2$ (13.6\% of the total variance of items), opposed the Angst-Free to the Health System Overload Anxious and World Conditions Anxious segment members as opposites. This opposition reveals a dimension related to the amplitude of fear from less distant to more distant groups in society. The biplot also reveals some distinctions between the types anxiety sources present in the Inside-Bubble Conditions Anxious segment compared to the others (e.g. greater preoccupations placed on pandemic impacts on personal health, household health, family stress and home violence).

Statistical Note: In the Chart 2 PCA bi-plot7, the first two principal components extracted from the data ( $\mathrm{C} 1$ and $\mathrm{C} 2)$ are shown. They are the most fundamental dimensions summarizing the activity patterns reported by respondents. In the biplot, vectors represent items which are presented as points in space. The bi-plot of the second component on the first component is useful as it displays the correlations of variables in terms of various item vectors of different magnitudes, directions and positions. Proximity of activity traits to group positions in space suggests an over-representation of these traits with respect to the composition of groups while greater distances suggests its converse. Correlations between two indicator variables in component space are equal to the cosines of the angles between the indicator vectors $(\theta)$, or $r=\cos (\theta)$. Highly correlated variables are located at sharp angles from each other $(\theta=90$ degrees or less) while those zero correlated are "orthogonal" to each other $(\theta=90$ degrees). If variables are perfectly negatively correlated, then $\theta=360$ degrees (vector in opposite direction).

7 PCA biplots were obtained using XLStat as statistical software. 
Chart 2: Biplot of Collective Anxieties Items and Population Segment Positions during the COVID-19 Pandemic, Canadians aged 15 years old and over

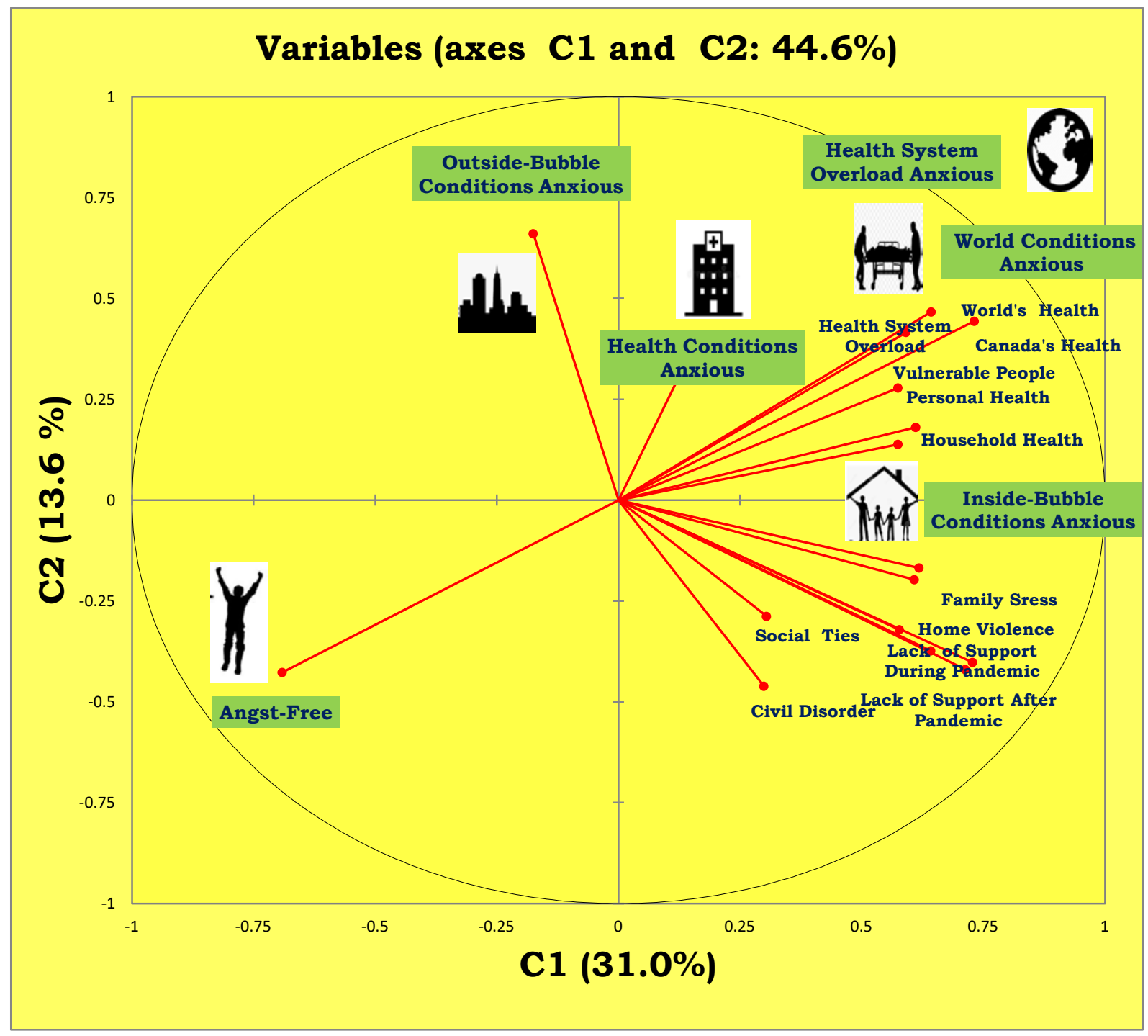

Source: CPSS-Series 1 Survey, Statistics Canada, 2020 
4.2. Segment Profile Summaries: Who Are they?

The following are the summary descriptions of the population segments found in the CPSS-Series3 data:

\section{Segment 1 - Health Conditions Anxious (13\% representing 3.9 million adult Canadians), Segment Motto: "Glad I Have A Health Card!"}

Members of this segment are particularly concerned about the state of health conditions in their households, Canada and the world. Top sources of anxiety for this group are vulnerable peoples' health and overloading the health system (3.72 and 3.52 score points on average respectively). Individuals belonging to this segment displayed an average score of 2.66 points across all 12 scale items. About $71 \%$ are married or living in common law status with a slight over-representation of women in their midst (55\%). About a third (30\%) had a level of education equivalent to a bachelor level or beyond while $40 \%$ were employed at work at least part of the reference week. The mental health pictured revealed that about one in four $(24 \%)$ reported either a poor or fair state of mental health.

\section{Segment 2 - Health System Overload Anxious (26\% representing 8.2 Million adult Canadians), Segment Motto: "How Many Beds Do We Have?"}

About one quarter of Canadians belong to this population segment. In terms of anxiety sources, these individuals appear similar to those in the previous segment but are particularly concerned with the issue of the potential overload of the health system in Canada (3.40 score points on average). The collapse of the system is a "nightmarish" situation for segment members. They displayed an average score of 2.70 points across all 12 scale items. With a slight over-representation of women (55\%), it is a relatively younger segment: $40 \%$ were 35 years old or under at the time of the survey. About 35\% reported to be single while $45 \%$ had a level of education equivalent to high school diploma or lower. About one in five (21\%) reported a poor or fair state of mental health.

\section{Segment 3 - Angst-Free (23\% representing 7.1 million adult Canadians), Segment Motto:"I'm Not Worried!"}

Angst-free individuals are not particularly concerned with any societal impacts of the pandemic in Canada and show relatively low levels of anxiety compared to members of the other five population segments. The reason for why this is the case may range from an enhanced sense of personal security, perceived low infection risks or explicit minimization of the extent of the pandemic as a problem for society. They displayed the lowest average score across all 12 anxiety scales: 1.87 points. This segment has a slight over-representation of males (58\%) and lower levels of education equivalent to high school diplomas or below (40\%). More than half (52\%) were employed at work for at least part of the reference week and $46 \%$ reported home as their work location. About one in ten of them $(13 \%)$ reported either a poor or a fair state of mental health. 


\section{Segment 4 - Inside-Bubble Conditions Anxious (12\% representing 3.7 million adult Canadians), Segment Motto: "My Bubble May Be In Trouble!"}

Like members of other segments, these individuals worried about the health impacts of the pandemic but single out pandemic impacts closer to the household "bubble" 8 as sources for anxiety. The family appears as the central foci of concern. Pandemic impacts in terms personal health, other household members' health, maintaining social ties and family stress were ranked among the top sources of anxiety for the inside-bubble anxious individuals (rating these items above 3.00 scale points on average). Individuals who are members of this segment rated home violence at a higher level compared to other segment members: average scale score of 1.78 points. Overall, the inside-bubble anxious group represents the most troubled one of the six segments: they scored the highest average points across the 12 anxiety scale items: 3.40 points. There is a slight over-representation of females (55\%) and foreign-born individuals (36\%) in this population segment. About $17 \%$ of segment members reported either poor or fair levels of mental health.

\section{Segment 5 - Outside-Bubble Conditions Anxious (25\% representing 7.8 Adult Canadians), Segment Motto: "Other Bubbles May Be In Trouble!"}

One quarter of Canadians belong to this population segment. Like members of other segments, these individuals worry about the health and social impacts of the pandemic but focus their attention to those occurring outside the household "bubble" which include Canada and the world. These types of anxiety items are rated at a higher level compared to items related to impacts worrying inside-bubble segment members. Members of this segment scored, on average, 2.28 points across all 12 anxiety scale items. About two thirds of them were married or living with a common law partner (65\%) while almost a third (31\%) had an equivalent university bachelor or above diploma. About $17 \%$ of them reported either a poor or fair level of mental health.

\section{Segment 6 - World Conditions Anxious (1\% representing 0.4 Million Adult Canadians), Segment Motto: "It's The End Of The World As We Know it!"}

Members of this small segment constitute genuine "outliers" in the spectrum of collective anxieties in Canada. They are troubled about all kinds of pandemic impacts but especially about impacts on the world's population health (average scale score points: 3.36). For them, the COVID-19 virus is a potential "threat" to the survival of humanity. With a majority of males in its midst, it is heavily over-represented by older individuals ( $81 \%$ were aged 65 years old and over), and foreign-born individuals (42\%). About 49\% of them reported having a high school diploma equivalent or below. Out of the six segment members, it has the least number of individuals reporting poor or fair levels of mental health (8\%).

\footnotetext{
8 A "bubble" is an unofficial term used in Canada to describe people with whom the individual feels comfortable spending time during the pandemic.
} 
Table 2: Collective Anxiety Domain Scales (Average Score) Reported by the Six Population Segments, Canada 2020

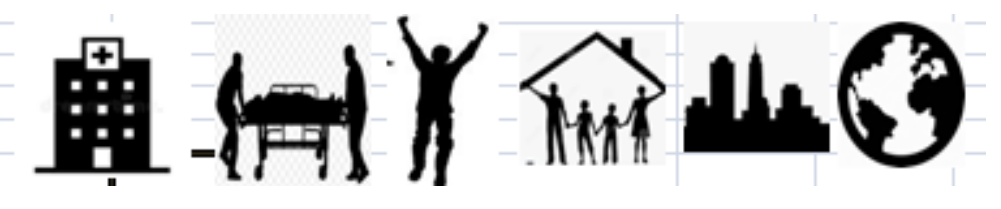

\begin{tabular}{|c|c|c|c|c|c|c|c|}
\hline Collective Anxiety Domain Items & 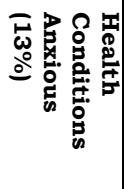 & 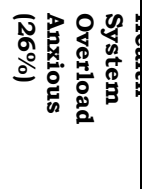 & 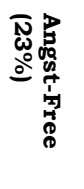 & 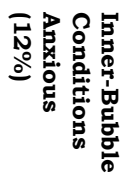 & 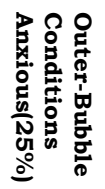 & 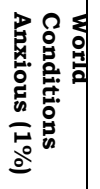 & 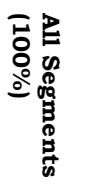 \\
\hline 1. Overloading the health system & 3.52 & 3.40 & 2.46 & 3.85 & 3.50 & 2.67 & 3.28 \\
\hline 2. Vulnerable peoples' health & 3.72 & 3.21 & 2.50 & 3.84 & 3.12 & 2.83 & 3.16 \\
\hline 3. World population's health & 3.22 & 2.96 & 2.01 & 3.73 & 3.20 & 3.36 & 2.93 \\
\hline 4. Canadian population's health & 3.26 & 2.94 & 1.99 & 3.76 & 3.07 & 3.03 & 2.90 \\
\hline 5. Member of household's health & 3.59 & 2.65 & 2.09 & 3.69 & 2.27 & 3.02 & 2.66 \\
\hline 6. Civil disorder & 2.34 & 2.75 & 1.79 & 3.50 & 2.10 & 2.53 & 2.40 \\
\hline 7. Able to cooperate during crisis & 2.28 & 2.89 & 1.80 & 3.61 & 1.83 & 2.84 & 2.38 \\
\hline 8. My own health & 3.24 & 2.24 & 1.81 & 3.37 & 2.06 & 2.58 & 2.36 \\
\hline 9. Able cooperate after crisis & 2.07 & 2.85 & 1.69 & 3.60 & 1.72 & 2.89 & 2.28 \\
\hline 10. Maintaining social ties & 2.07 & 2.73 & 1.68 & 3.29 & 1.72 & 2.66 & 2.21 \\
\hline 11. Family stress & 2.01 & 2.56 & 1.75 & 3.29 & 1.71 & 2.41 & 2.17 \\
\hline 12. Violence in the home & 1.12 & 1.49 & 1.16 & 1.78 & 1.07 & 1.00 & 1.29 \\
\hline
\end{tabular}


11

Table 3: Socio-Demographic, Residential, Employment and Health Profiles of the Six Population Segments, Canada 2020

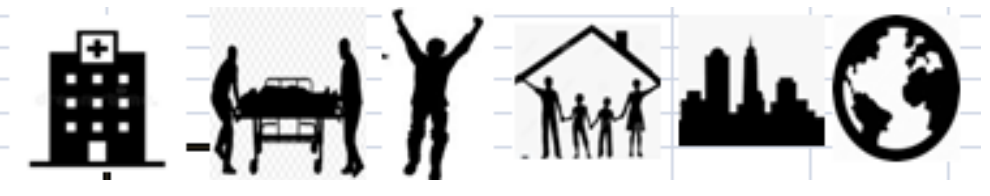

\begin{tabular}{|c|c|c|c|c|c|c|c|}
\hline $\begin{array}{l}\text { Socio-Demographic, } \\
\text { Residential, } \\
\text { Employment and } \\
\text { Health Profiles }\end{array}$ & 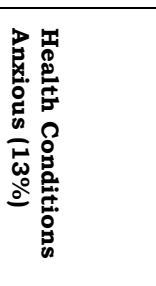 & 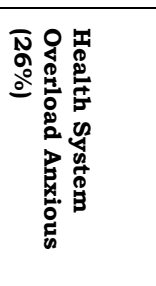 & 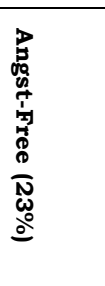 & 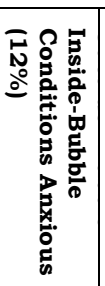 & 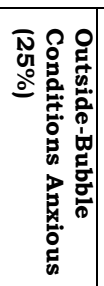 & 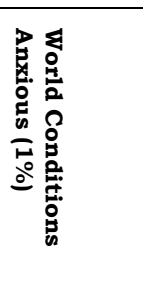 & 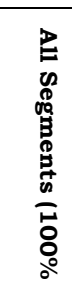 \\
\hline$\% 35$ years old or under & $20 \%$ & $40 \%$ & $29 \%$ & $28 \%$ & $32 \%$ & $2 \%$ & $31 \%$ \\
\hline$\% 65+$ years old & $29 \%$ & $18 \%$ & $19 \%$ & $17 \%$ & $21 \%$ & $81 \%$ & $21 \%$ \\
\hline$\%$ Female & $55 \%$ & $55 \%$ & $42 \%$ & $55 \%$ & $53 \%$ & $46 \%$ & $52 \%$ \\
\hline \% Married- Common Law & $71 \%$ & $57 \%$ & $62 \%$ & $67 \%$ & $65 \%$ & $64 \%$ & $63 \%$ \\
\hline$\%$ Single Marital status & $16 \%$ & $35 \%$ & $28 \%$ & $23 \%$ & $26 \%$ & $16 \%$ & $27 \%$ \\
\hline$\%$ Foreign-born & $26 \%$ & $28 \%$ & $19 \%$ & $36 \%$ & $15 \%$ & $42 \%$ & $24 \%$ \\
\hline $\begin{array}{l}\text { \% Living in a household with } \\
\text { a child } 18 \text { years old or under }\end{array}$ & $29 \%$ & $39 \%$ & $33 \%$ & $\mathbf{3 8} \%$ & $33 \%$ & 9\% & $35 \%$ \\
\hline $\begin{array}{l}\text { \% High School Diploma or } \\
\text { less }\end{array}$ & $32 \%$ & $45 \%$ & $40 \%$ & $44 \%$ & $39 \%$ & $49 \%$ & $41 \%$ \\
\hline $\begin{array}{l}\% \text { University education } \\
\text { equivalent to bachelor or } \\
\text { more }\end{array}$ & $30 \%$ & $25 \%$ & $28 \%$ & $28 \%$ & $31 \%$ & $17 \%$ & $28 \%$ \\
\hline $\begin{array}{l}\text { \% Living in apartment } \\
\text { building }\end{array}$ & $25 \%$ & $17 \%$ & $16 \%$ & $23 \%$ & $18 \%$ & $25 \%$ & $19 \%$ \\
\hline $\begin{array}{l}\text { \% Employed at work for at } \\
\text { least part of the reference } \\
\text { week }\end{array}$ & $40 \%$ & $43 \%$ & $52 \%$ & $44 \%$ & $46 \%$ & $15 \%$ & $45 \%$ \\
\hline$\%$ Work location at home & $32 \%$ & $38 \%$ & $46 \%$ & $27 \%$ & $45 \%$ & $10 \%$ & $39 \%$ \\
\hline $\begin{array}{l}\text { \% Poor or Fair Level of } \\
\text { Overall Health }\end{array}$ & $11 \%$ & $8 \%$ & $5 \%$ & $7 \%$ & $4 \%$ & $12 \%$ & $7 \%$ \\
\hline $\begin{array}{l}\text { \% Poor or Fair Level of } \\
\text { Mental Health }\end{array}$ & $24 \%$ & $21 \%$ & $13 \%$ & $17 \%$ & $17 \%$ & $8 \%$ & $18 \%$ \\
\hline
\end{tabular}




\subsection{Reflections}

One major contribution of psychographic market segmentation analysis like the one carried out in this study is the discovery of hidden attitudinal patterns and the ability to link statistical methods to the monitoring of outcomes during the COVID-19 pandemic in Canada. A statistical portrait of COVID-19 collective anxieties can help federal, regional and local decision makers to better identify specific and universal market segments and tailor segment-suited interventions. Rather than "one size fits all" results, public health programs and activities can be developed for each population cluster and provide tools that can change perceptions and develop more effective responses to tackle positive and negative outcomes in the always-changing COVID-19 confinement environment.

The concept of collective anxieties emerging during pandemics such as the COVID-19 in Canada is closely connected with other concepts such personal experiences, perceptions of the prevalence of the disease in the general population and anxiety about life in general. Some people are more anxious about the fate of people located close to their personal networks while others about more geographically or socially distant groups of people (i.e. variations in the "amplification" principle proposed by Hume (2000)). This study suggests that ego-oriented or kin-oriented types of anxieties may be somewhat different with respect to more broader altruistic ones. Regardless of these orientations, however, the state of the health system seems to be central foci of concern for most Canadians during the COVID-19 pandemic. Although this study focused on the psychographics present at the start of the pandemic (March-April 2020), the health system overload issue is expected to be a central source of anxiety across all stages of the pandemic in Canada.

Given that collective anxieties are city or region specific, more geographically focused studies are desirable. It should be noted that the available public version of the CPSSSeries 1 survey, regrettably, did not contain provincial or territorial breakdowns and was limited to individual reporting during the "first" phase of the pandemic. In the "second" and subsequent phases of the pandemic, shifts in the share of segment composition are likely to occur. More frequent surveys carried out by Statistics Canada and/or other data collection agencies may yield, in the future, important information on the common transitions of individuals from one cluster to another.

In light of the market segmentation findings, what population segments deserve special attention in terms of public policy? The answer to this question depends on the nature of the intended public messages and the attitudinal traits of the groups themselves. Segment 1 and 2 are anxious about the capacity of the Canadian health system to deal with the human toll of the pandemic while members of segment 4 (inside-bubble conditions), the most anxious group, are troubled by the fragility of the personal and household networks and the safety of family and relatives. A higher level of fear and anxiety often leads to negative outcomes such as mental health deterioration and low personal efficacy (see for instance the work of Zajacova et. al (2020) with CPSS Series 1 data). Overall, all segments including the Outside-Bubble Conditions Anxious, the AngstFree and World Conditions Anxious, need to be targeted by messages empowering individuals by providing greater information on the different avenues to cope with infections, the progress in controlling the pandemic and appropriate sanitary guidelines. 


\subsection{References}

Chin-Feng, L. (2002). Segmenting Customer Brand Preference: Demographic or Psychographic", Journal of Product \& Brand Management, Vol. 11 (4) pp. 249 - 268.

Da Silva, M; Barbosa-Rocha, R; Buheji, M.; Jahrami, H.; and Costa-Cuhna, K. (2020). A Systematic Review of the Prevalence of Anxiety Symptoms During Coronavirus Epidemics, Journal of Health Psychology 1 (11).

Grover, R and Vriens, M (2006), A Guide to the Design and Execution of Segmentation Studies, The Handbook of Marketing Research, Sage Publishing.

Hume, J. (2000). The Forgotten 1918 Influenza Epidemic and Press Portrayal of Public Anxiety, Journalism and Mass Communication Quarterly, Vol 77 (4),pp.898-915.

Hunt, A. (1999) Anxiety and Social Explanation: Some Anxieties about Anxiety, Journal of Social History, Vol. 32 (3),

Punj, G., \& Stewart, D. (1983). Cluster analysis in marketing research: Review and suggestions for application. Journal of Marketing Research, 20, pp. 134-148.

Salkind, N.J., and Rasmussen, K. (2010). k-Means Cluster Analysis, Encyclopedia of Measurement and Statistics: Sage Publishing

Strong, P. (1990) Epidemic Psychology: A Model. Sociology of Health and Illness, Vol. 12(3), pp.249-59.

Tynan, C.A. and Drayton, J.(1987). Market Segmentation. Journal of Marketing Management (2) No.3, pp.301-335

World Health Organization-WHO. (2020) . Mental Health and Psychosocial Considerations During COVID-19 Outbreak; World Health Organization: Genève, Switzerland, 2020.

Zajacova, A.; Jehn, A.; Stackhouse, J.; Choi, K; Denice, P.; Haan, M and Ramos, H. (2020). Mental Health and Economic Concerns from March to May during the COVID-19 Pandemic in Canada, Socarxiv papers: https://osf.io/preprints/socarxiv/76me2 
7.0. Technical Appendix

Chart A-1: Within Class Sum of Squares Variation Ratio for Various Cluster Solutions

\section{Within Class Sum of Squares Variation Ratio(WSS)}

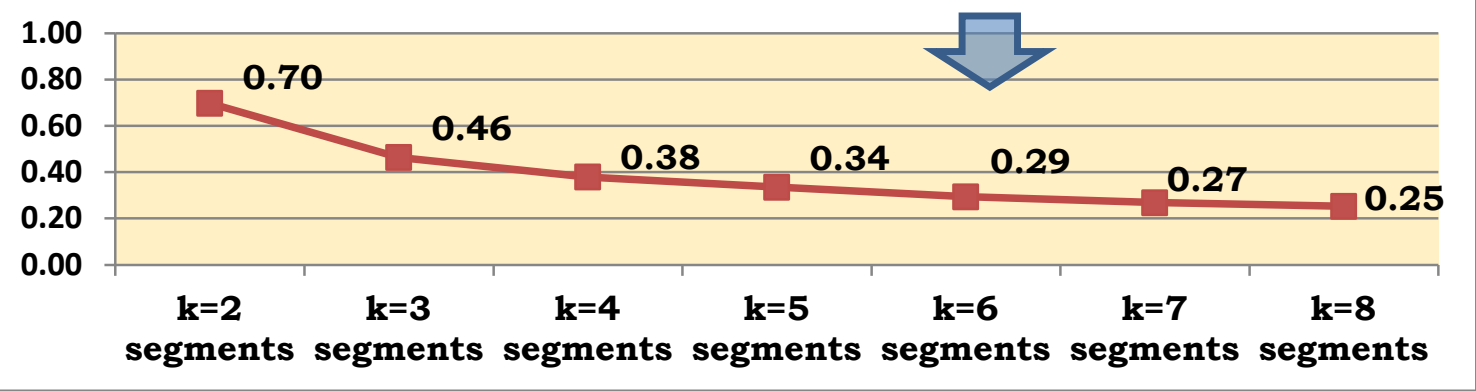

Source: CPSS-Series 1 Survey, Statistics Canada, 2020

Table A-2:ANOVA F tests predicting Socio-Demographic, Residential, Employment and Health Related Characteristics of CPSS-Series 1 Survey Respondents

\begin{tabular}{|l|r|r|r|r|r|l|}
\hline ANOVA Test Results & SS & d.f & Mean Square & F Ratio & Sig. & R Square \\
\hline Age Groups & 114516.3 & 5 & 22903.3 & 75021.0 & 0.00 & 0.02 \\
Education Level & 60032.2 & 5 & 12006.4 & 18481.6 & 0.00 & 0.01 \\
Gender & 68683.7 & 5 & 13736.7 & 56052.3 & 0.00 & 0.02 \\
Marital status & 229618.8 & 5 & 45923.8 & 27779.3 & 0.00 & 0.01 \\
Type of dwelling & 181560.3 & 5 & 36312.1 & 26680.5 & 0.00 & 0.01 \\
Employment status & 185355.1 & 5 & 37071.0 & 69013.8 & 0.00 & 0.02 \\
Child under 18 resides in dwelling & 17839.0 & 5 & 3567.8 & 14895.8 & 0.00 & 0.00 \\
Household size & 27411.4 & 5 & 5482.3 & 5734.1 & 0.00 & 0.00 \\
Immigration status & 92532.0 & 5 & 18506.4 & 107253.3 & 0.00 & 0.03 \\
Telework Status & 470821.5 & 5 & 94164.3 & 78283.8 & 0.00 & 0.02 \\
Perceived Health Status & 297298.0 & 5 & 59459.6 & 81553.5 & 0.00 & 0.02 \\
Perceived Mental Health Status & 661131 & 5 & 132226.2 & 116672.5 & 0.00 & 0.03 \\
& & & & & & \\
\hline
\end{tabular}

